\title{
Clinical significance of ASB9 in human colorectal cancer
}

\author{
MASAYOSHI TOKUOKA ${ }^{1 *}$, NORIKATSU MIYOSHI ${ }^{1 *}$, TOSHIKI HITORA $^{1 *}$, KOSHI MIMORI $^{2}$, \\ FUMIAKI TANAKA $^{2}$, KOICHI SHIBATA ${ }^{2}$, HIDESHI ISHII ${ }^{1}$, MITSUGU SEKIMOTO ${ }^{1}$, \\ YUICHIRO DOKI $^{1}$ and MASAKI MORI ${ }^{1}$ \\ ${ }^{1}$ Department of Gastroenterological Surgery, Osaka University Graduate School of Medicine; ${ }^{2}$ Department of \\ Surgical Oncology, Medical Institute of Bioregulation, Kyushu University, Suita, Osaka, Japan
}

Received March 12,2010; Accepted May 3, 2010

DOI: 10.3892/ijo_00000762

\begin{abstract}
Ankyrin repeat and SOCS box-containing 9 (ASB9) is involved in the negative regulation of cytokine signaling. However, its biological function is largely undefined. The aim of this study was to assess the value and role of ASB9 as an indicator of prognosis in colorectal cancer (CRC). In order to demonstrate the importance of ASB9 expression for predicting the prognosis of $\mathrm{CRC}$, we analyzed the ASB9 mRNA expression in 125 paired cases of CRC and noncancerous regions and the protein expression by immunohistochemistry. To investigate the role of ASB9 in vitro, we performed proliferation and invasion assay with small interfering RNA against ASB9. ASB9 mRNA expression was higher in $\mathrm{CRC}$ tissue than corresponding normal tissue $(\mathrm{P}=0.0282)$. Patients expressing low levels of ASB9 had a poorer overall survival rate than those expressing high levels $(\mathrm{P}=0.0301)$, indicating that decreased ASB9 expression was an independent prognostic factor. The immunohistochemical study revealed that ASB9 was predominantly expressed in cancer cells. A multivariate analysis showed that ASB9 expression status was an independent prognostic factor of overall survival (relative risk, 4.09; 95\% confidence interval, 1.47-11.88; $\mathrm{P}=0.007)$. In an invasion assay, ASB9 siRNAtransfected cells showed significantly high invasiveness. The results of the present study suggest that ASB9 is a useful prognostic marker for CRC.
\end{abstract}

\section{Introduction}

Cancer is a major public health problem in developed countries. In recent years, the incidence of colorectal cancer (CRC) has significantly increased with changes in lifestyle and CRC is now one of the most frequent causes of death from neoplastic

Correspondence to: Dr Masaki Mori, Department of Gastroenterological Surgery, Osaka University Graduate School of Medicine, 2-2 Yamadaoka, Suita, Osaka 565-0871, Japan

E-mail:mmori@gesurg.med.osaka-u.ac.jp

*Contributed equally

Key words: ASB9, gastrointestinal cancer, colorectal cancer disease in Japan (1). Identifying genes responsible for the development and progression of CRC and understanding their clinical significance is critical to the diagnosis and adequate treatment of the disease.

ASBs such as ASB5 and ASB8 have been reported to play a role in the initiation of arteriogenesis and cell growth $(2,3)$ However, ASB9 is involved in the negative regulation of cytokine signaling (4), its functions in colorectal cancer is unknown. ASB9 was reported to have close relation to CKB. Creatine kinase $\mathrm{B}(\mathrm{CKB})$ is over-expressed in a wide range of solid tumors and has been used as a prognostic marker of cancer and metastasis (5). The CKB gene is positively regulated by the oncogene E1a and negatively regulated by the tumor suppressor gene p53 (6,7). Thus, many growth factors and hormones, such as estrogen, stimulate CKB activity and expression $(8,9)$. Estrogen has been shown to induce the expression of $\mathrm{CKB}$ in the reproductive tract of female rats and human breast tumors and tissues (10). We hypothesized that ASB9 expression is a prognostic factor for CRC patients. We analyzed the ASB9 gene in 125 paired cases of CRC and non-cancerous regions, proposing an importance of ASB9 expression in evaluating prognosis and suggesting it as a novel candidate marker for CRC.

\section{Materials and methods}

Clinical tissue samples. A total of 125 patients (45 men, 80 women) with CRC underwent surgery at the Medical Institute of Bioregulation at Kyusyu University from 1992 to 2002. Primary CRC specimens and adjacent normal colorectal mucosa were obtained from patients after receiving informed consent in accordance with institutional guidelines. Every patient was definitively identified as having CRC based on clinicopathological findings. The resected surgical specimens were fixed in formalin, processed through graded ethanol, embedded in paraffin, sectioned with hematoxylin and eosin (H\&E) stain and Elastica van Gieson stain, and the degree of the histological differentiation, lymphatic invasion and venous invasion examined. Immediately after resection, all specimens were frozen in liquid nitrogen and kept at $-80^{\circ} \mathrm{C}$ until RNA extraction was performed.

None of the patients received chemotherapy or radiotherapy prior to surgery. After surgery, the patients were followed up with blood analysis, including serum tumor 
markers carcinoembryonic antigen (CEA) and cancer antigen (CA19-9), and imaging modalities, such as abdominal ultrasonography and/or computed tomography and chest X-ray, every 3-6 months. Clinicopathological factors were assessed according to the criteria of the Tumor-Node-Metastasis (TNM) classification of the International Union Against Cancer (UICC) (11).

$R N A$ preparation and reverse transcription $(R T)-P C R$. Total RNA was prepared using a modified acid guanidium-phenolchloroform procedure with DNAse (12). Reverse transcription was performed using $2.5 \mu \mathrm{g}$ of total RNA as described previously (13). Two human ASB9 oligonucleotide primers were designed for the PCR reaction: 5'-CCTGGCATCAGGC TTCTTTC-3' (forward) and 5'-ACCCCTGGCTGATGAGG TTC-3' (reverse). To confirm adequate PCR products, 35 cycles of PCR were performed using a PCR kit (Takara, Kyoto, Japan) on a GeneAMP PCR system 9600 (PE Applied Biosystems, Foster City, CA) with the following parameters: $95^{\circ} \mathrm{C}$ for $40 \mathrm{sec}, 45^{\circ} \mathrm{C}$ for $40 \mathrm{sec}$, and $72^{\circ} \mathrm{C}$ for $60 \mathrm{sec}$. An $8-\mu 1$ aliquot of each reaction mixture was size-fractionated in a $1.5 \%$ agarose gel and visualized by ethidium bromide staining. To ensure that the RNA was not degraded, PCR specific to glyceraldehyde-3-phosphate dehydrogenase $(G A P D H)$ was performed using 30 cycles of $1 \mathrm{~min}$ at $95^{\circ} \mathrm{C}, 1 \mathrm{~min}$ at $56^{\circ} \mathrm{C}$, and $1 \mathrm{~min}$ at $72^{\circ} \mathrm{C}$ and the following primers: $5^{\prime}$-TTGG TATCGTGGAAGGACTCA-3' (forward) and 5'-TGTCAT CATATTGGCAGGTT-3' (reverse). A 270-bp amplicon was produced. cDNA from the human reference total RNA (Clontech, Palo Alto, CA, USA) was studied concurrently as a source of positive controls.

Quantitative real-time PCR. Real-time PCR monitoring was performed using the LightCycler FastStart DNA Master SYBR-Green I kit (Roche Diagnostics, Tokyo, Japan). The amplification protocol for ASB9 and GAPDH cDNA consisted of 35 cycles of denaturation at $95^{\circ} \mathrm{C}$ for $10 \mathrm{sec}$, annealing at $62^{\circ} \mathrm{C}$ for $10 \mathrm{sec}$, and elongation at $72^{\circ} \mathrm{C}$ for $10 \mathrm{sec}$. The products were then subjected to a temperature gradient from $55^{\circ} \mathrm{C}$ to $95^{\circ} \mathrm{C}$ at $0.1^{\circ} \mathrm{C} / \mathrm{sec}$ with continuous fluorescence monitoring to produce a melting curve for the products. The ratio of ASB9 mRNA copies in tumor and normal tissues was calculated and normalized against GAPDH.

Immunohistochemistry. Surgical specimens from formalinfixed, paraffin-embedded tissues were used for immunohistochemistry. After deparaffinization and blocking, the antigenantibody reaction was incubated overnight at $4^{\circ} \mathrm{C}$. Reagent (Envision, Dako Cytomation, Denmark) was applied to detect the signal from the antigen-antibody reaction. All sections were counterstained with hematoxylin. Primary antiASB9 mouse monoclonal antibody (WH0140462M1, Sigma Aldrich) was used at a dilution of 1:200. All sections were independently examined for protein expression and scored as positive when $>10 \%$ of cancer tissues were stained in an examined area of a specimen and negative when $<10 \%$ was stained.

Cell lines and culture. Three cell lines derived from human CRC (CaCo-2, HCT116 and SW480) were obtained from the
American Type Culture Collection (Manassas, VA). Cells were maintained in Dulbecco's minimal essential medium (DMEM) containing $10 \%$ fetal bovine serum and antibiotics at $37^{\circ} \mathrm{C}$ in a $5 \%$ humidified $\mathrm{CO}_{2}$ atmosphere. For siRNA inhibition, double-stranded RNA duplexes targeting human ASB9 and negative control siRNA (NC) were purchased in a Stealth RNAi kit (Invitrogen, Carlsbad, CA, USA): 5'-GCC UGUCUUGGAGGUCAUCUCUCUU-3' and 5'-UAUUAAA GCAUGGAGCUCAGGUGAA-3', 5'-CAGCCACCUGGGC ACUCCACUCUAU-3' and 5'-GGCUUCCAGAAGAUCUA CAAGCAAU-3', and 5'-ACGGGCGAAUUGAGUUGUCC GAGUU-3' and 5'-GACAUUGUGGAUGCCAUUUACC AGA-3'. The CRC cell lines were transfected with siRNA at a concentration of $20 \mu \mathrm{mol} / 1$ using lipofectamine RNAiMAX (Invitrogen), incubated in glucose-free Opti-MEM (Invitrogen), treated in accordance with the manufacturer's protocols, and analyzed by proliferation and invasion assay after $48 \mathrm{~h}$. All siRNA duplexes were used together in a triple transfection. The culture growth rate was measured by counting cells using a CellTac kit (Nihon Koden, Tokyo, Japan). Each transfected cell line was compared to the wild-type and NC. Values were expressed as the standard error of the mean (SEM) of at least three independent experiments.

Proliferation assays. To assess proliferation, cells were grown an additional $24 \mathrm{~h}$ in DMEM containing 10\% FBS. Cell viability was determined using the Cell Counting kit incorporating WST-8 (Dojindo Lab., Tokyo, Japan). WST-8 (10 $\mu 1)$ was added to $100 \mu \mathrm{l}$ of medium containing each supplement above, and the absorbance was read at $450 \mathrm{~nm}$ using a microplate reader (Model 680XR; Bio-Rad Laboratories, Hercules, CA, USA). All experiments were performed at $30-80 \%$ cell confluence and the results confirmed in at least three independent experiments.

Invasion assays. Cell invasion was assessed using the CytoSelect Cell Invasion Assay according to the manufacturer's protocol (Cell Biolabs, San Diego, CA) $48 \mathrm{~h}$ after transfection. Cells $\left(1.0 \times 10^{5}\right)$ in DMEM were placed on an $8.0-\mu \mathrm{m}$ pore size membrane inserted in 96-well plates. DMEM with $10 \%$ FBS was placed in the bottom wells. After $24 \mathrm{~h}$, non-invading cells were removed from the top side of the membrane chamber, and the cells from the underside of the membrane were completely dislodged by tilting the membrane chamber in Cell Detachment Solution (Cell Biolabs). Lysis buffer/ CyQuannt GR dye solution (Cell Biolabs) was added to each well, the fluorescence of the mixture was read with a fluorescence plate reader at $480 \mathrm{~nm} / 520 \mathrm{~nm}$. The values are expressed as a ratio to control (each parental cell).

Statistical analysis. For continuous variables, the data are expressed as the mean $\pm \mathrm{SD}$. The relationship between mRNA expression and clinicopathological factors was analyzed by the Chi-square test and Student's t-test. Kaplan-Meier survival curves were plotted and compared with the generalized logrank test. Univariate and multivariate analyses for the identification of prognostic factors for overall survival were performed using the Cox proportional hazard regression model. The tests were analyzed using JMP software (SAS Institute, Cary, NC, USA). Significance was set at $\mathrm{P}<0.05$. 
Table I. Clinicopathological factors and ASB9 mRNA expression in 125 colorectal cancers.

\begin{tabular}{|c|c|c|c|}
\hline Factors & High expression (\%) & Low expression $(\%)$ & P-value \\
\hline \multicolumn{4}{|c|}{ Age (years) } \\
\hline$<68$ & $34(54.8)$ & $28(44.4)$ & 0.245 \\
\hline$\geq 68$ & $28(45.2)$ & $35(55.6)$ & \\
\hline \multicolumn{4}{|l|}{ Gender } \\
\hline Male & $24(38.7)$ & $21(33.3)$ & 0.531 \\
\hline Female & $38(61.3)$ & $42(66.7)$ & \\
\hline \multicolumn{4}{|c|}{ Histological grade ${ }^{a}$} \\
\hline Well & $21(33.9)$ & $24(38.1)$ & 0.628 \\
\hline Others $^{b}$ & $41(66.1)$ & 39 (61.9) & \\
\hline \multicolumn{4}{|c|}{ Tumor size (mm) } \\
\hline$<50$ & $30(48.4)$ & $37(58.7)$ & 0.246 \\
\hline$\geq 50$ & $32(51.6)$ & $26(41.3)$ & \\
\hline \multicolumn{4}{|l|}{ Depth } \\
\hline T0-3 & $43(69.4)$ & $40(63.5)$ & 0.488 \\
\hline $\mathrm{T} 4$ & $19(30.6)$ & $23(36.5)$ & \\
\hline \multicolumn{4}{|c|}{ Lymph node metastasis } \\
\hline Absent & $35(56.5)$ & $36(57.1)$ & 0.938 \\
\hline Present & $27(43.5)$ & $27(42.9)$ & \\
\hline \multicolumn{4}{|c|}{ Lymphatic invasion } \\
\hline Absent & $37(59.7)$ & $42(66.7)$ & 0.418 \\
\hline Present & $25(40.3)$ & $21(33.3)$ & \\
\hline \multicolumn{4}{|c|}{ Venous invasion } \\
\hline Absent & $51(82.3)$ & $52(82.5)$ & 0.967 \\
\hline Present & $11(17.7)$ & $11(17.5)$ & \\
\hline \multicolumn{4}{|l|}{ Metastasis } \\
\hline M0 & $56(90.3)$ & $52(82.5)$ & 0.204 \\
\hline M1 & $6(9.7)$ & $11(17.5)$ & \\
\hline
\end{tabular}

${ }^{\text {a}}$ Well, well-differentiated adenocarcinoma; b ${ }^{\text {Others: }}$ moderately-differentiated adenocarcinoma, poorly-differentiated adenocarcinoma and mucinous carcinoma.

\section{Results}

Relationship between ASB9 mRNA expression and clinicopathological characteristics. For the clinicopathological evaluation, the experimental samples were divided into 2 groups according to expression status. Patients with a tumor ASB9/ GAPDH ratio of expression above the median were assigned to the high expression group $(n=62)$; others were assigned to the low expression group $(n=63)$. Clinicopathological factors related to ASB9 expression status are summarized in Table I. The number of cases with histological grades of well, moderate, poor and mucinous adenocarcinoma was $45,71,6$ and 3 , respectively. The number of cases with UICC stages 0 , I, IIA, IIB, IIIA, IIIB, IIIC and IV was 6, 21, 31, 10, 5, 24, 6 and 22, respectively. The data indicate that the expression of ASB9 was not correlated with clinicopathological factors.
Relationship between ASB9 expression and prognosis. The data show that the overall survival rate was significantly higher in patients expressing elevated levels of ASB9 (Fig. 1). The median follow up was $9.98 \pm 2.94$ years. Table II presents the univariate and multivariate analyses of factors related to patient prognosis. Univariate analysis showed that the following factors were significantly related to overall survival: tumor depth $(\mathrm{P}<0.001)$, lymph node metastasis $(\mathrm{P}=0.001)$, lymphatic invasion $(\mathrm{P}=0.001)$, venous invasion $(\mathrm{P}=0.004)$ and ASB9 mRNA expression $(\mathrm{P}=0.013)$. Multivariate analysis indicated that inclusion in the high expression group [relative risk (RR) 4.09; 95\% confidence interval (CI) 1.47-11.88; $\mathrm{P}=0.007]$, tumor invasion (RR 5.03; 95\% CI 1.86-13.58; $\mathrm{P}=0.001)$, and lymph node invasion (RR $4.31 ; 95 \%$ CI $1.60-11.63 ; \mathrm{P}=0.004)$ were independent predictors of overall survival. 


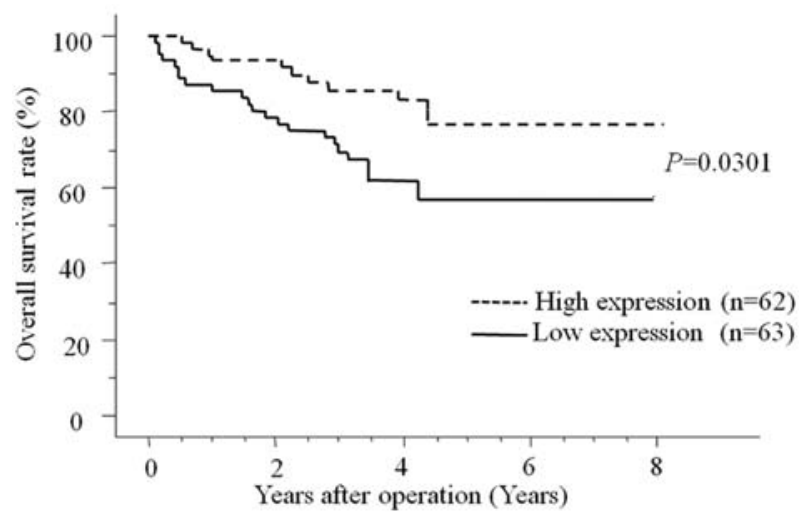

Figure 1. Survival curves of patients with colorectal cancer according to the status of ASB9 mRNA expression. Patients with low ASB9 expression had a significantly poorer prognosis than those with high ASB9 expression. $\mathrm{P}<0.0301$ using the log-rank test.

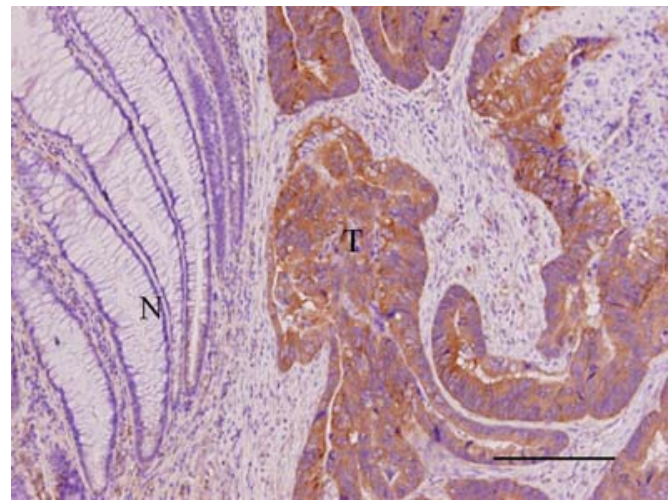

Figure 2. Positive staining observed in the cytoplasm of cancer cells, but not the stromal cells, indicating that the cancer cells are positive for ASB9 expression. A representative negative stain for ASB9 in a normal colorectal specimen shows normal glandular cells. ASB9 protein expression was evaluated in tumors and corresponding normal tissues from 23 colorectal cancer cases. Original magnification $\mathrm{x} 40 . \mathrm{T}$, tumor cells; $\mathrm{N}$, normal glandular cells. Scale bar $=200 \mu \mathrm{m}$.

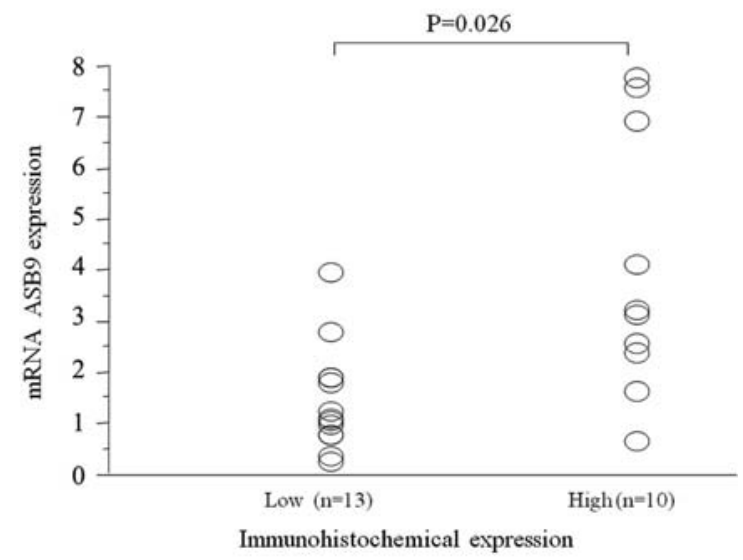

Figure 3. Relationship between ASB9 mRNA and immunohistochemistry in tissue samples from 23 colorectal cancer cases. Higher ASB9 mRNA expression was observed in the group with a higher immunohistochemistry expression $(n=10)$ compared to the low expression group $(n=13)$. ASB9 mRNA expression was significantly associated with protein expression ( $\mathrm{P}=0.026$ with the Student's t-test). The expression ratio of ASB9 mRNA was calculated and normalized against GAPDH.
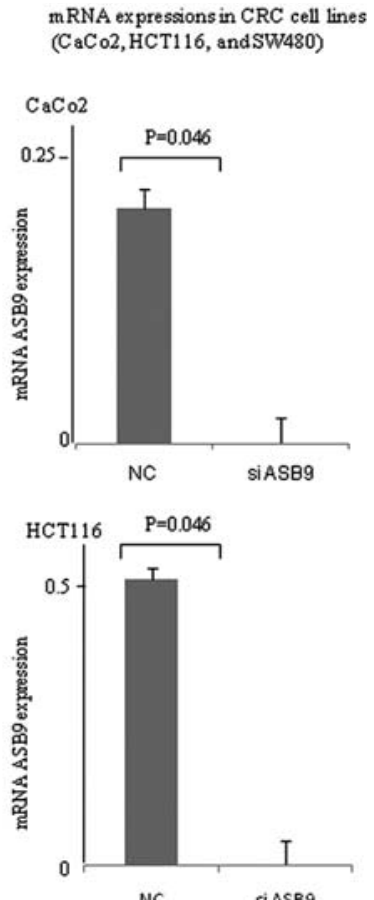

NC SIASB9

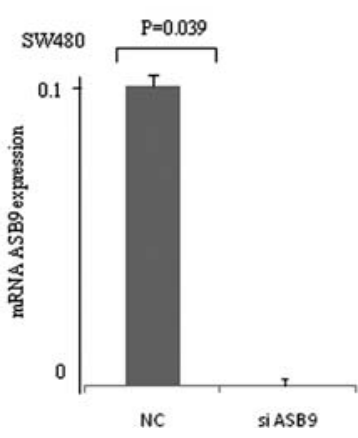

Figure 4. ASB9 mRNA knockdown by siRNA in CaCo2, HCT116 and SW480 cells. A significant reduction in ASB9 mRNA expression by siRNA was confirmed by quantitative real-time RT-PCR in CaCo2, HCT116 and SW480 cells. The data are presented as mean \pm SD of four independent experiments. The expression levels were normalized to GAPDH mRNA expression.

Immunohistochemistry. ASB9 protein staining was observed predominantly in the cytoplasm of cancer cells and undetectable in the stromal cells of colorectal tumors (Fig. 2). Of 125 total cases, we examined ASB9 protein expression status in 23 available patient samples that analyzed by RTPCR. Significantly higher ASB9 mRNA expression was observed in the group with high immunohistochemistry expression $(n=10)$ compared to the low expression group $(\mathrm{n}=13)(\mathrm{P}=0.026$, Student's t-test; Fig. 3). Thus, the level of ASB9 mRNA expression was associated with the level of protein expression.

In vitro assessment of the knockdown of ASB9 expression. Three CRC cell lines were chosen for the proliferation and invasion studies. A significant reduction in ASB9 using siRNA was confirmed by quantitative real-time RT-PCR (Fig. 4). No significant differences in $\mathrm{CaCo} 2$ and SW480 cell numbers were measured in the proliferation assay between NC and ASB9 siRNA-transfected cells, whereas significant 
Proliferation assay
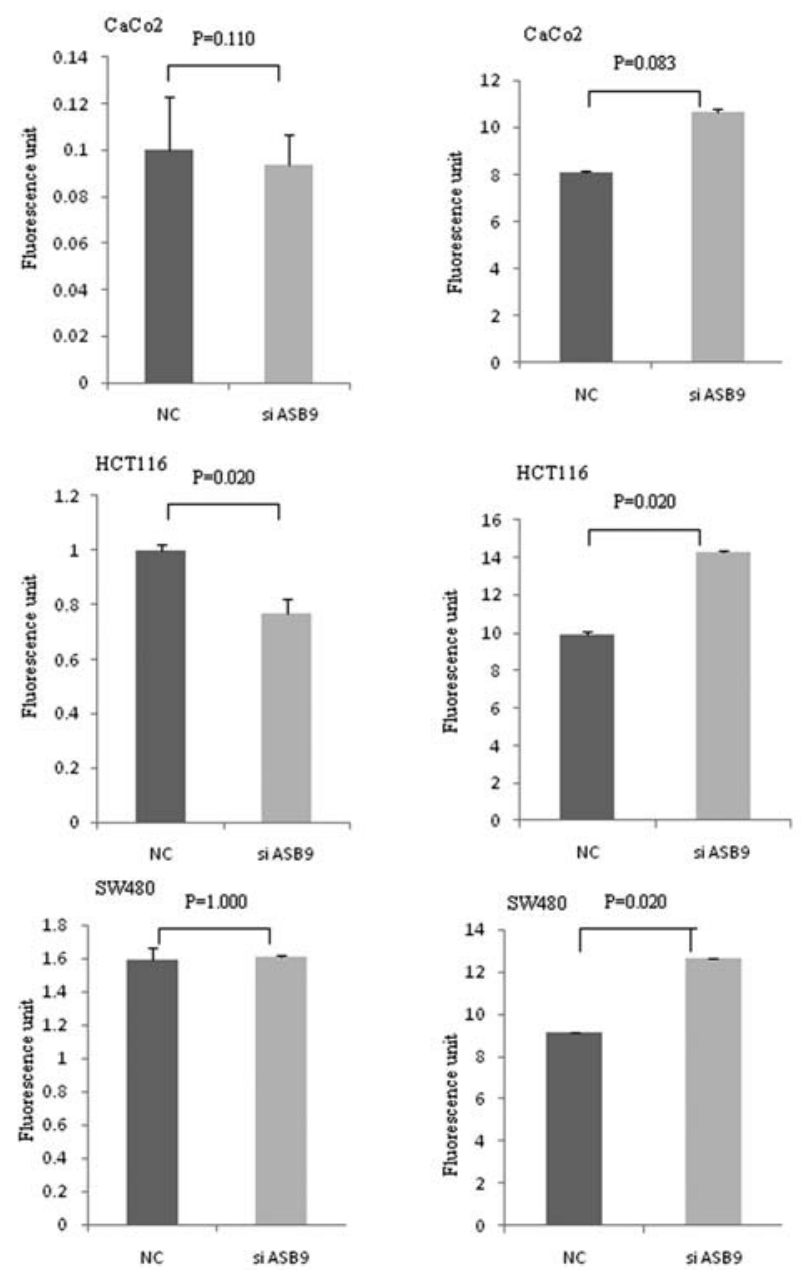

Figure 5. Cellular proliferation and invasion after ASB9 knockdown by siRNA. Top, no significant differences were measured in $\mathrm{CaCo} 2$ and SW480 between negative control (NC) and ASB9 siRNA-transfected cells. Bottom, ASB9 siRNA-transfected cells exhibited significantly high penetration of cells through the Matrigel-coated membrane compared to NC in HCT116 and SW480 cells. The data are presented as mean \pm SD of three independent experiments.

differences were noted in HCT116 (n=4, Fig. 5). In the invasion assay, the results showed significant differences in HCT116 and SW480 cells between NC and ASB9 siRNAtransfected cells but no significant differences in $\mathrm{CaCo} 2$ cells $(n=4$, Fig. 5).

\section{Discussion}

ASB proteins constitute the largest family of SOCS boxcontaining proteins with 18 identified murine and human ASBs, but their biological and biochemical functions are largely unknown. The ASBs contain a protein interaction motif composed of a variable number of ankyrin repeats upstream from the SOCS box that is found in eukaryotic, bacterial and viral proteins, including receptors, proteins involved in cell cycle regulation, secreted proteins and transcription factors $(14,15)$. The ASBs have been implicated in different biological processes. ASB-1 was studied by utilizing genetically modified mice; although ASB-1 knockout mice displayed some testicular anomalies, the deletion and over-expression of ASB-1 had no obvious effect on mouse development (16). On the other hand, ASB-2 may regulate myeloid cell proliferation and/or differentiation $(17,18)$, ASB-5 possibly plays a role in the initiation of arteriogenesis (2), and ASB-11 may regulate the proliferation and differentiation of the developing nervous system (3). Also, ASB-15 has been reported to regulate muscle growth by acting as a negative regulator of proliferating muscle cells and by increasing the rate of protein synthesis in differentiated myoblasts $(19,20)$ ASB-8 expression is undetectable in normal adult lung tissue but present in several lung carcinoma cell lines. The transfection of a possible dominant negative form of ASB-8 suppressed the growth of lung adenocarcinoma cells in vitro, implying an association of ASB-8 with the development of lung cancer (20). In the present study, high ASB9 mRNA expression correlated with a good prognosis (Fig. 1). In addition, multivariate analysis identified ASB9 mRNA expression as a significant prognostic factor (Table II). In a previous report, high ASB9 expression was shown to reduce endogenous CKB (4). CKB, also known as the brain-type cytosolic enzyme of creatine kinase, plays a major role in cellular energy metabolism in non-muscle cells (5). Over-expression of CKB has been observed in a number of tumors, including neuroblastoma, small cell lung carcinoma, colon and rectal adenocarcinoma, and breast and prostate carcinoma, as well as some tumor cell lines $(5,6)$. Furthermore, wild-type p53 represses the CKB promoter (7). In fact, many human small cell lung carcinomas, which exhibit elevated CKB expression, contain mutations in the p53 alleles (5). Therefore, elevated ASB9 may result in a good prognosis for CRC through reduced CKB. The interaction of ASB9 with CKB and the implied roles of ASB2 and ASB8 in other cancers $(17,18,20)$ indicate that ASB9 may also have a role in tumor development or progression with CKB. However, no study has been conducted previously regarding the role of ABS9 in CRC.

Recently, the necessity of intensive follow-up and adjuvant therapy for CRC was proposed for predicting recurrence and metastasis in curative surgically resected cases (21-23). For these cases, prognostic markers of tumor invasion and metastasis play a very important role in cancer treatment. The expression profile of ASB9 may contribute to a certain type of prognostic factor.

Multivariate analysis indicated that inclusion in the high expression group, tumor depth and lymph node invasion were independent predictors of overall survival (Table II). We investigated the malignant potentials in proliferation and invasion assay (Fig. 5). The present in vitro study showed that the down-regulation of ASB9 by siRNA increased cell invasion in HCT116 and SW480 cells but was not related to tumor growth in $\mathrm{CaCo} 2$ and SW480 cells. Tumor size was not significantly different between the high and low ASB9 expression groups, supporting the data from the proliferation assay. We also found that the down-regulation of ASB9 significantly induced cell invasiveness. The low expression group had more T4 and M1 cases compared to the high expression group. In addition, multivariate analysis showed 
Table II. Univariate and multivariate analysis for overall survival (Cox proportional hazards regression model).

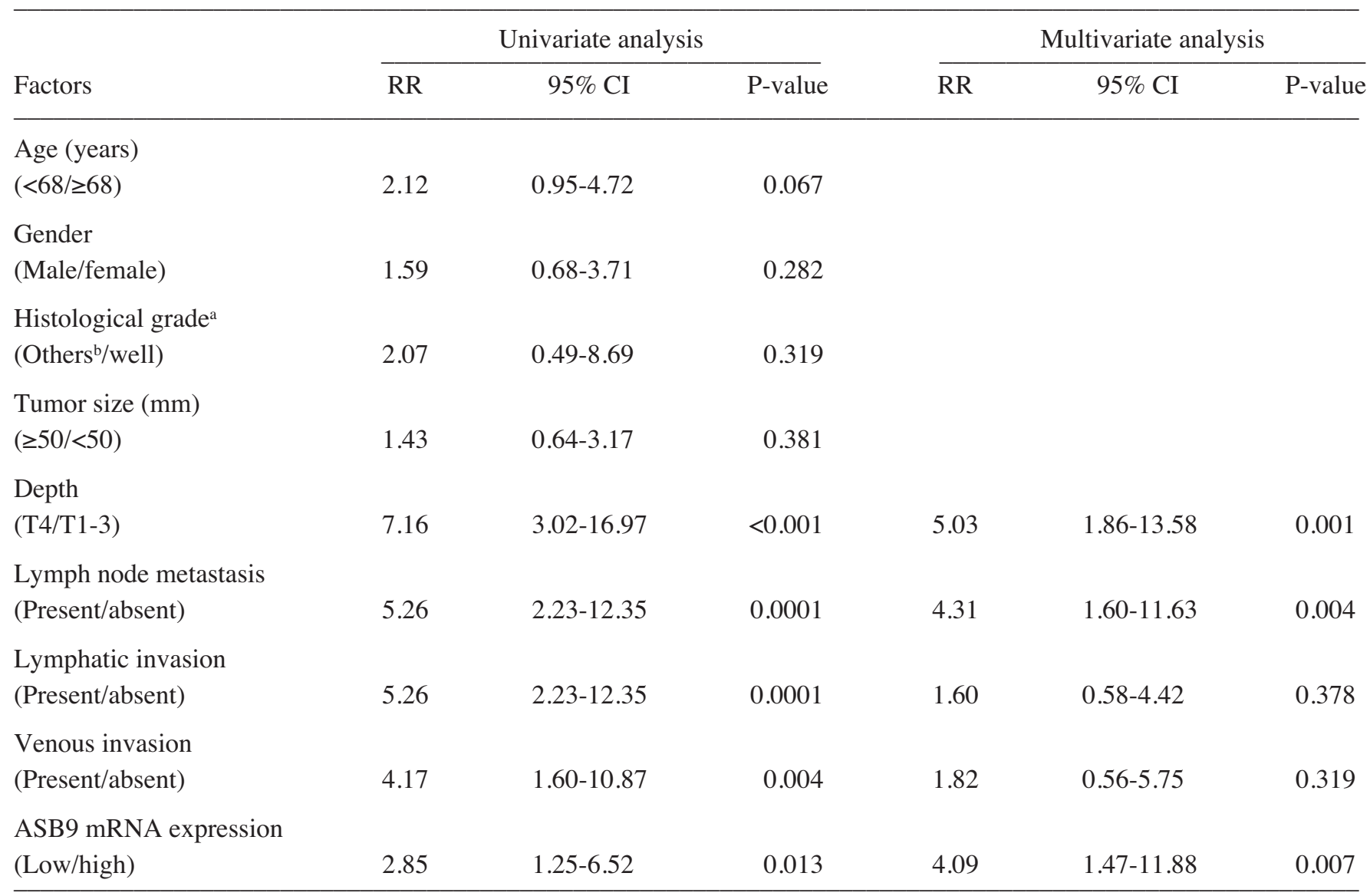

${ }^{a}$ Well, well-differentiated adenocarcinoma; ' ${ }^{\text {Others: }}$ moderately-differentiated adenocarcinoma, poorly-differentiated adenocarcinoma, and mucinous carcinoma. RR, relative risk; CI, confidence interval.

that ASB9 mRNA expression is a significant prognostic factor for overall survival. Thus, low ASB9 expression may have higher malignant potential, such as cell invasiveness and liver metastasis, than high expression, resulting in a poor prognosis for CRC. However, an analysis of upregulated ASB9 expression and further in-depth studies are needed to investigate the precise molecular mechanism underlying the cause and effect between ASB9 and CRC. To our knowledge, this is the first report showing the role of ASB9 in cancer and its usefulness as a novel marker of CRC prognosis, implying that it may contribute to prediction of prognosis and to treatment.

\section{References}

1. Kohno SI, Luo C, Nawa A, Fujimoto Y, Watanabe D, Goshima F, Tsurumi T and Nishiyama Y: Oncolytic virotherapy with an HSV amplicon vector expressing granulocyte-macrophage colony-stimulating factor using the replication-competent HSV type 1 mutant HF10 as a helper virus. Cancer Gene Ther 14: 918-926, 2007.

2. Boengler K, Pipp F, Fernandez B, Richter A, Schaper W and Deindl E: The ankyrin repeat containing SOCS box protein 5: a novel protein associated with arteriogenesis. Biochem Biophys Res Commun 302: 17-22, 2003.

3. Diks SH, Bink RJ, van de Water S, Joore J, van Rooijen C, Verbeek FJ, den Hertog J, Peppelenbosch MP and Zivkovic D: The novel gene Asb11: a regulator of the size of the neural progenitor compartment. J Cell Biol 174: 581-592, 2006.
4. Debrincat MA, Zhang JG, Willson TA, Silke J, Connolly LM, Simpson RJ, Alexander WS, Nicola NA, Kile BT and Hilton DJ: Ankyrin repeat and suppressors of cytokine signaling box protein Asb-9 targets creatine kinase B for degradation. J Biol Chem 282: 4728-4737, 2007.

5. Wyss $M$ and Kaddurah-Daouk R: Creatine and creatinine metabolism. Physiol Rev 80: 1107-1213, 2000.

6. Wallimann $\mathrm{T}$ and Hemmer W: Creatine kinase in non-muscle tissues and cells. Mol Cell Biochem 133-134: 193-220, 1994.

7. Zhao J, Schmieg FI, Simmons DT and Molloy GR: Mouse p53 represses the rat brain creatine kinase gene but activates the rat muscle creatine kinase gene. Mol Cell Biol 14: 8483-8492, 1994.

8. Somjen D, Weisman Y, Harell A, Berger E and Kaye AM: Direct and sex-specific stimulation by sex steroids of creatine kinase activity and DNA synthesis in rat bone. Proc Natl Acad Sci USA 86: 3361-3365, 1989.

9. Ch'ng JL and Ibrahim B: Transcriptional and posttranscriptional mechanisms modulate creatine kinase expression during differentiation of osteoblastic cells. J Biol Chem 269: 2336$2341,1994$.

10. Wang F, Samudio I and Safe S: Transcriptional activation of rat creatine kinase B by 17 beta-estradiol in MCF-7 cells involves an estrogen responsive element and GC-rich sites. J Cell Biochem 84: 156-172, 2001.

11. Sobin LH and Fleming ID: TNM classification of malignant tumors, fifth edition (1997). Union Internationale Contre le Cancer and the American Joint Committee on Cancer. Cancer 80: 1803-1804, 1997.

12. Mimori K, Mori M, Shiraishi T, Fujie T, Baba K, Haraguchi M, Abe R, Ueo $\mathrm{H}$ and Akiyoshi T: Clinical significance of tissue inhibitor of metalloproteinase expression in gastric carcinoma. Br J Cancer 76: 531-536, 1997. 
13. Mori M, Staniunas RJ, Barnard GF, Jessup JM, Steele GD and Chen Jr LB: The significance of carbonic anhydrase expression in human colorectal cancer. Gastroenterology 105: 820-826, 1993.

14. Kile BT, Viney EM, Willson TA, Brodnicki TC, Cancilla MR, Herlihy AS, Croker BA, Baca M, Nicola NA, Hilton DJ and Alexander WS: Cloning and characterization of the genes encoding the ankyrin repeat and SOCS box-containing proteins Asb-1, Asb-2, Asb-3 and Asb-4. Gene 258: 31-41, 2000.

15. Bork P: Hundreds of ankyrin-like repeats in functionally diverse proteins: mobile modules that cross phyla horizontally? Proteins 17: 363-374, 1993

16. Kile BT, Metcalf D, Mifsud S, DiRago L, Nicola NA, Hilton DJ and Alexander WS: Functional analysis of Asb-1 using genetic modification in mice. Mol Cell Biol 21: 6189-6197, 2001.

17. Guibal FC, Moog-Lutz C, Smolewski P, Di Gioia Y, Darzynkiewicz Z, Lutz PG and Cayre YE: ASB-2 inhibits growth and promotes commitment in myeloid leukemia cells. J Biol Chem 277: 218-224, 2002.

18. Kohroki J, Fujita S, Itoh N, Yamada $\mathrm{Y}$, Imai $\mathrm{H}$, Yumoto $\mathrm{N}$, Nakanishi T and Tanaka K: ATRA-regulated Asb-2 gene induced in differentiation of HL-60 leukemia cells. FEBS Lett 505: 223-228, 2001
19. McDaneld TG, Hannon K and Moody DE. Ankyrin repeat and SOCS box protein 15 regulates protein synthesis in skeletal muscle. Am J Physiol Regul Integr Comp Physiol 290: 1672-1682, 2006.

20. Liu Y, Li J, Zhang F, Qin W, Yao G, He X, Xue P, Ge C, Wan D and $\mathrm{Gu} \mathrm{J}$ : Molecular cloning and characterization of the human ASB-8 gene encoding a novel member of ankyrin repeat and SOCS box containing protein family. Biochem Biophys Res Commun 300: 972-979, 2003.

21. Wolpin BM and Mayer RJ: Systemic treatment of colorectal cancer. Gastroenterology 134: 1296-1310, 2008.

22. Kornmann M, Formentini A, Ette C, Henne-Bruns D, Kron M, Sander S, Baumann W, Kreuser ED, Staib L and Link KH. Prognostic factors influencing the survival of patients with colon cancer receiving adjuvant 5-FU treatment. Eur J Surg Oncol 34: 1316-1321, 2008.

23. Bathe OF, Dowden S, Sutherland F, Dixon E, Butts C, Bigam D, Walley B, Ruether D and Ernst S: Phase II study of neoadjuvant 5-FU + leucovorin + CPT-11 in patients with resectable liver metastases from colorectal adenocarcinoma. BMC Cancer 4: 32, 2004. 